\title{
Mock-up Test of Time Lag in Floor Heating Systems with PCM
}

\author{
Sung Ho Choi ${ }^{1}$, Tae Won $\mathrm{Kim}^{2}$ and Jin Chul Park ${ }^{3 *}$ \\ ${ }^{1,2}$ Graduate School, Chung-Ang University, 06974, Korea \\ ${ }^{3}$ School of Architecture and Building Science, Chung-Ang University, 06974, Korea
}

\begin{abstract}
This research analyzes the time lag, which is a thermal storage performance parameter, when a phase change material is applied to the floor heating system of a mock-up laboratory. The following results are obtained. In terms of the time required for the floor surface temperature to reach $30^{\circ} \mathrm{C}$, the time lag of Room 2 (i.e., the room with the PCM-based floor system) was observed to be $15 \mathrm{~min}$. Additionally, in terms of the time required for the floor surface temperature to decrease to $22{ }^{\circ} \mathrm{C}$, Room 2 exhibited a time lag of $5 \mathrm{~h} 2 \mathrm{~min}$. Therefore, the study concluded that longer time lags are observed with floor heating systems with PCM.
\end{abstract}

\section{Introduction}

In the Republic of Korea, a majority of residential structures are equipped with floor heating systems[1]. More specifically, in the cases of radiant floor heating systems, hot water is used as the heat source in concretebased systems compared to cases in other countries where a dry construction method is adopted[2]. However, such floor heating systems are susceptible to a radical temperature decrease when their hot water supply is halted because of the low thermal storage performance of lightweight foamed concrete and mortar[3].

In this study, the time lag, which is a thermal storage performance characteristic, of a conventional floor heating system and a system equipped with phase change material was comparatively analyzed in a mock-up laboratory. The results of this study may be used to provide basic data to improve the thermal storage performance of floor heating systems, and in turn their energy performance.

\section{Mock-up Test}

\subsection{Construction of Mock-up Test Room}

To analyze the effect of phase change material (PCM) on the time lag of a floor heating system, a mock-up test room is fabricated. The mock-up consists of two rooms. Each room has a floor area of $3.6 \mathrm{~m} 2$ and a net volume of $8.6 \mathrm{~m} 3$ (Table 1); these are the minimal area and volume requirements for a single-person household. Furthermore, each room was surrounded by a $200 \mathrm{~mm}$ thick insulation layer that prevented thermal exchange with the exterior environment. Room 1 uses a standard floor structure applied in conventional residential floor systems, and Room 2 uses a floor structure with PCM.
Table 1. Specifications of rooms.

\begin{tabular}{|c|c|}
\hline Room size & $2 \mathrm{~m} \times 1.8 \mathrm{~m} \times 2.4 \mathrm{~m}(\mathrm{~W} \times \mathrm{L} \times \mathrm{H})$ \\
\hline Room volume & $8.6 \mathrm{~m} 3$ \\
\hline Floor area & $7.2 \mathrm{~m} 2(3.6 \mathrm{~m} 2$ per room) \\
\hline External conditions & Identical (Indoor mock-up) \\
\hline \multirow{2}{*}{ Room Composition } & Room 1: Conventional floor heating \\
\cline { 2 - 2 } & Room 2: PCM Floor heating (RT42) \\
\hline Boiler operation & $70^{\circ} \mathrm{C}$ for $18 \mathrm{~h}$ \\
\hline
\end{tabular}

To measure the thermal storage performance, thermal sensors were installed at several locations such as the upper part of the PCM, floor finish surface, mortar surface, and inside the room, as shown in Fig. 1. Each sensor measured the temperature of the component. Floor cross sections of the two rooms are shown in Figures 1 and 2.

The temperature measurement locations include the surface of the hot water pipes, the upper part of the PCM, the floor finish surface, and a point located $1200 \mathrm{~mm}$ from the mortar surface. The sensors used for temperature measurement were T-type thermocouples (T0.32-Y-W-15), and a Graphte Midi Logger GL820 was used to collect data every minute.

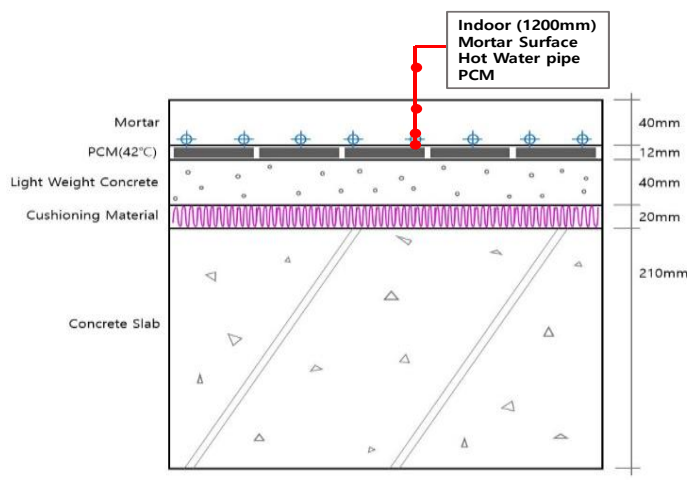

Fig. 1. PCM floor heating system (Sensor locations)

\footnotetext{
${ }^{*}$ Corresponding author: jincpark@cau.ac.kr
} 


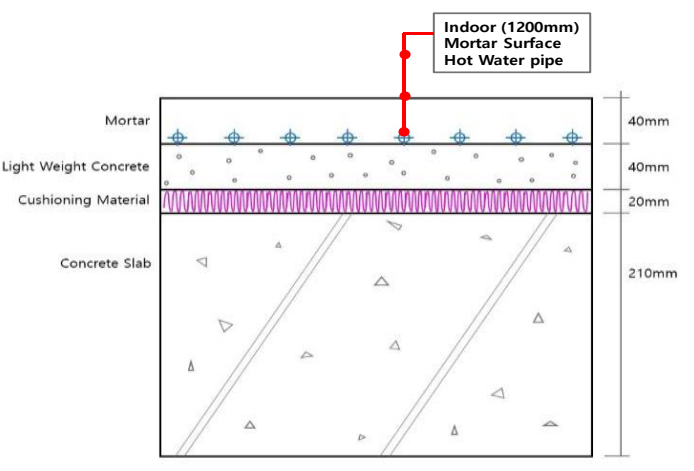

Fig. 2. conventional floor heating system (Sensor locations)

\subsection{Measurement results}

The time taken for the temperature to reach $30^{\circ} \mathrm{C}$ was used to determine the time lag; the time lag was used for a comparative analysis between Room 1 (the room with a conventional floor heating system) and Room 2 (the room with a floor heating system with PCM). Results of previous research have shown that the floor surface temperature should reach $30^{\circ} \mathrm{C}$ to maintain a comfortable room temperature in winter $\left(22^{\circ} \mathrm{C}\right)[4]$.

After analyzing the time required for the floor surface temperature of each room to reach $30^{\circ} \mathrm{C}$, the following results were obtained. The time required for Room 1 was $4 \mathrm{~h} 50 \mathrm{~min}$ and that for Room 2 was $5 \mathrm{~h} 5 \mathrm{~min}$; it was observed that the time lag in Room 2 owing to the PCM was $15 \mathrm{~min}$. Moreover, the time taken for the floor surface temperature of Rooms 1 and 2 to decrease to $22{ }^{\circ} \mathrm{C}$ after heating supply was halted was recorded as follows: Room 1 took $11 \mathrm{~h} 41 \mathrm{~min}$ and Room 2 took 16 h 43 min. It was be observed that the time lag in Room 2 owing to PCM was $5 \mathrm{~h}$ and $2 \mathrm{~min}$.

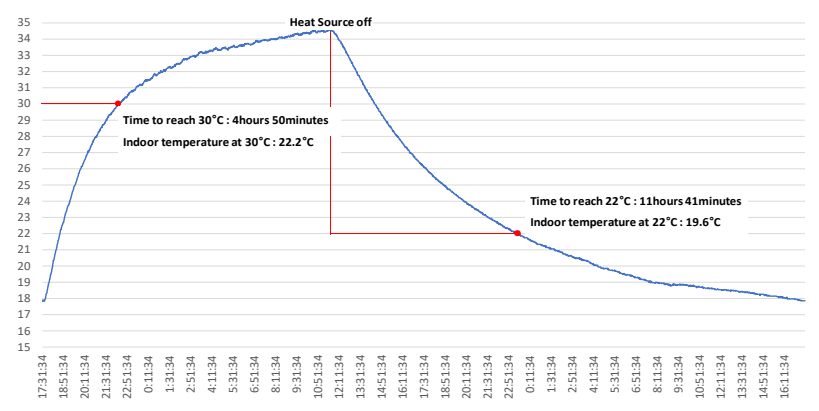

Fig. 3. Room 1: Temperature at mortar surface

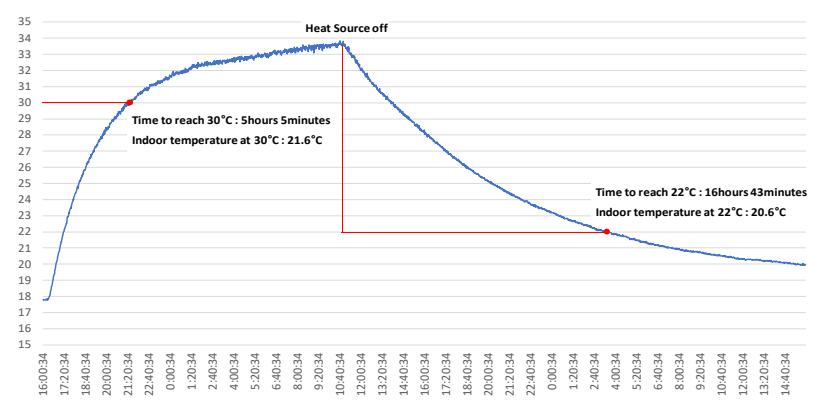

Fig. 4. Room 2: Temperature at mortar surface

\section{Conclusions}

This research analyzes the time lag of a floor surface system when PCM was applied in a mock-up laboratory system. This was compared to the thermal storage performance of a conventional floor system, and the following results were obtained.

In terms of the time required for the floor surface temperature to increase to $30{ }^{\circ} \mathrm{C}$, Room 1 took $4 \mathrm{~h} 50$ min, while Room 2 (with PCM-based floor system) took $5 \mathrm{~h} 5 \mathrm{~min}$. Thus, the time lag of Room 2 owing to PCM was observed to be $15 \mathrm{~min}$. In terms of the time required for the floor surface temperature to decrease to $22{ }^{\circ} \mathrm{C}$, Room 1 took $11 \mathrm{~h} 41 \mathrm{~min}$ and Room 2 took 16 h 43 min; it was observed that Room 2 (with a PCM-based floor system) took 5 h 2 min longer than Room 1.

\section{Acknowledgments}

This research was supported by the Basic Science Research Program through the National Research Foundation of Korea (NRF) funded by the Ministry of Education (no. 2016R1D1A1B01015616).

\section{References}

1. Architecture \& Urban Research Institute, Status of greenhouse gas emissions and policy trends in Korean buildings (2010)

2. S. M. Kim, H. J. Kim., Thermal stability and viscoelastic properties of MF/PVAc hybrid resins on the adhesion for engineered flooring under heating system ONDOLO, Thermochimica Acta, Vol. 444, pp. 134-140 (2006)

3. B. C. Ahn, T. W. Lee, Strategy of energy saving and thermal environment improvement for intermittent heating system in apartment buildings, Korean Journal of Air-Conditioning and Refrigeration Engineering, Vol. 17, No. 1, pp. 88-94 (2005)

4. S. H. Baek., Reduce domestic greenhouse gas emissions by $32.5 \%$ over BAU-amendment of the basic roadmap for national greenhouse gas reduction minimization of international reduction amount compensated by domestic reduction measures, Electric Power Journal, Electric Power Vol. 12, No. 7, pp. 50-53 (2018) 